\title{
KALIBRACIJA I VERIFIKACIJA NUMERIČKOG MODELA OTICAJA I EROZIJE
}

Ognjen Gabrić ${ }^{1}$

UDK: $551.311 .21: 001.891 .54$

DOI: $10.14415 /$ zbornikGFS28.08

Rezime: Na bazi terenskih i laboratorijskih merenja, a uporedo sa razvojem računarske tehnike, razvijeni su i modeli oticaja i erozije zasnovani na rešavanju jednačina kojima se opisuje fizika procesa. Uzimajući model KINEROS2 kao osnovu, u radu su prikazani osnovni principi modeliranja procesa oticaja $i$ erozije zasnovani na rešavanju diferencijalnih jednačina kojima se opisuje fizika procesa. Takeđe, prikazane su $i$ alternativne jednačine za obračun otpora trenja, članova izvora i ponora za pokretanje odnosno taloženje erodovanih čestica i transportnog kapaciteta. Numerički modeli zasnovani na originalnim i alternativnim jednačinama su kalibrisani $i$ verifikovani na laboratorijskom modelu. Rezultati ukazuju da bi sastavni deo modela oticaja i erozije morao biti $i$ obračun otpora trenja korišćenjem analitičkog rešenja za tečenje $u$ laminarnoj zoni.

Ključne reči: erozija, model, oticaj

\section{UVOD}

Istraživanja na laboratorijskim slivovima sa jedne strane i razvoj primenjene matematike i računarske tehnike sa druge, uticali su na razvoj metoda matematskog modeliranja procesa oticaja i erozije. Zbog velikog broja činilaca koji utiču na proces, njihove međuzavisnosti i promenljivosti po prostoru i vremenu, još uvek nije razvijen model koji bi zadovoljio u svim uslovima i svim potrebama. Iz uporedne analize nekoliko modela oticaja i erozije [2] može se zaključiti da matematički modeli oticaja i erozije uglavnom koriste pojednostavljene St. Venant-ove jednačine za simulaciju procesa oticaja, odnosno jednačine ustaljenog i neustaljenog transporta nanosa za simulaciju erozije.

Čest je slučaj i da se u numeričkim modelima, parametri modela bazirani na jednačinama koje opisuju fiziku procesa, kalibrišu na osnovu merenja [5]. Na ovaj način se može doći do tačnih (merenih) vrednosti oticaja, međutim problem se javlja pri određivanju dubine odnosno brzine vode što kasnije ima posledice na proračun pokretanja i transporta nanosa. Dosadašnja iskustva u primeni modela KINEROS2 ukazuju da je model oticaja osetljiv na promenu koeficijenta filtracije i Manning-ovog koeficijenta hrapavosti dok je model erozije i transporta nanosa u najvećoj meri osetljiv na faktor erodibilnosti zemljišta [8]. Slični rezultati dobijeni su i uporednom kalibracijom modela KINEROS2 i modela GSSHA [6].

\footnotetext{
${ }_{1}^{1}$ dr Ognjen Gabrić, diplomirani građevinski inženjer, Građevinski fakultet Subotica, Kozaračka 2a, 24000 Subotica, Srbija, e-mail: ogabric@gf.uns.ac.rs
} 
U radu je prikazan numerički model sastavljen po uzoru na model KINEROS2, njegova kalibracija i verifikacija na osnovu laboratorijskog merenja oticaja i erozije sa sliva. Osim standardne kalibracije modela pomoću koeficijenta filtracije, Manning-ovog koeficijenta i faktora erodibilnosti zemljišta, u radu je prikazana i mogućnost primene analitičkog rešenja proračuna otpora trenja u laminarnoj zoni kao elementa kalibracije modela.

\section{TEORIJSKE OSNOVE MODELIRANJA OTICAJA I EROZIJE}

\subsection{Model oticaja}

Praktično svi modeli oticaja polaze od de St. Venant-ovih jednačina za linijsko neustaljeno tečenje u otvorenim tokovima, koje čine:

jednačina kontinuiteta:

$$
\frac{\partial(\rho A)}{\partial t}+\frac{\partial(\rho u A)}{\partial x}=0
$$

dinamička jednačina:

$$
\frac{\partial(\rho u A)}{\partial t}+\frac{\partial\left(\rho u^{2} A\right)}{\partial x}=g \rho A \frac{\partial Z_{d n a}}{\partial x}-g \rho A \frac{\partial h}{\partial x}-\bar{\tau} O_{b}
$$

gde je $\rho$ gustina fluida $\left(\mathrm{kg} / \mathrm{m}^{3}\right), u$ brzina $(\mathrm{m} / \mathrm{s}), A$ površina poprečnog preseka $\left(\mathrm{m}^{2}\right), t$ vreme (s), $x$ rastojanje u pravcu toka $(\mathrm{m}), g$ gravitaciono ubrzanje $\left(\mathrm{m} / \mathrm{s}^{2}\right), Z_{d n a}$ kota dna $(\mathrm{mnm}), h$

dubina (m), $\tau$ tangencijalni napon $\left(\mathrm{N} / \mathrm{m}^{2}\right)$ i $O_{b}$ okvašeni obim (m).

Dinamička jednačina se može predstaviti i u alternativnom obliku koji se dobija tako što se iz razvijenog oblika:

$$
\underbrace{\rho A \frac{\partial u}{\partial t}}_{1}+\underbrace{u \frac{\partial(\rho A)}{\partial t}}_{2}+\underbrace{\rho A u \frac{\partial u}{\partial x}}_{3}+\underbrace{u \frac{\partial(\rho u A)}{\partial x}}_{4}=\underbrace{g \rho A \frac{\partial Z_{d n a}}{\partial x}}_{5}-\underbrace{g \rho A \frac{\partial h}{\partial x}}_{6}-\bar{\tau} O_{b}
$$

na osnovu jednačine kontinuiteta eliminiše se zbir članova (2) i (4), što daje:

$$
\frac{1}{g} \frac{\partial u}{\partial t}+\frac{u}{g} \frac{\partial u}{\partial x}=\underbrace{\frac{\partial Z_{d n a}}{\partial x}}_{3}-\frac{\partial h}{\partial x}-\frac{\bar{\tau}}{g \rho R}
$$

Pojednostavljeni oblici dinamičke jednačine ( 4 ) se dobijaju sukcesivnim zanemarivanjem članova: prvo zanemarenjem neustaljenog člana (1), zatim zanemarenjem advektivnog

\section{0} | JOURNAL OF FACULTY OF CIVIL ENGINEERING 28 (2015) | 
člana (2) i konačno zanemarenjem člana pritiska (4) čime se dobija oblik poznat i kao jednačina kinematskog talasa:

$$
\frac{\bar{\tau}}{\rho g R}=\frac{\partial Z_{d n a}}{\partial x}=S_{0}
$$

gde je $S_{0}$ nagib dna (-).

Prosečni napon trenja, $\bar{\tau}$, za poprečni presek se može izraziti na standardan način, preko prosečne brzine tečenja $(u)$, za poprečni presek i prosečnog koeficijent trenja $C \tau$ odnosno $\lambda$ za presek:

$$
\bar{\tau}=C_{\tau} \frac{\rho u^{2}}{2}=\frac{\lambda}{4} \frac{\rho u^{2}}{2}
$$

Leva strana jednačine ( 5 ) se onda može izraziti kao:

$$
\frac{\bar{\tau}}{\rho g R}=\frac{\frac{\lambda}{4} \frac{\rho u^{2}}{2}}{\rho g R}=\frac{\frac{\lambda}{8} u^{2}}{g R}=\frac{\lambda}{8 g R} u^{2}
$$

tako da jednačina ( 5 ) postaje:

$$
\frac{\lambda}{8 g R} u^{2}=S_{0}
$$

odakle se može dobiti veza srednje brzine u za presek i nagiba, koja uključuje koeficijent trenja i karakteristike strujanja:

$$
u=\sqrt{\frac{8 g}{\lambda}} \sqrt{R S_{0}}
$$

Slične veze daju i empirijski izrazi koji važe za ustaljeno tečenje kao što su Manning-ov:

$$
u=\frac{1}{n} R^{\frac{2}{3}} \sqrt{S_{0}}
$$

odnosno Chezy-jev izraz: 


$$
u=C \sqrt{R S_{0}}
$$

Oticaj po jedinici širine površine određuje se kao:

$$
q=u \cdot h
$$

gde je $q$ oticaj po jedinici širine $\left(\mathrm{m}^{2} /(\mathrm{s} \mathrm{m})\right), u$ brzina $(\mathrm{m} / \mathrm{s}), h$ dubina vode u preseku $(\mathrm{m})$. Model KINEROS2 kao rudimentarni oblik dinamičke jednačine koristi ili Manning-ov ili Chezy-jev izraz ( 10 ) i ( 11), dok je jednačina kontinuiteta ( 1 ), uz pretpostavku da su gustina fluida i širina elementa oticaja konstantne, iskazana kao:

$$
\frac{\partial h}{\partial t}+\frac{\partial q}{\partial x}=i-f
$$

gde su na desnoj strani dodati članovi kojima se definiše intenzitet padavina $(i)$ i infiltracija $(f)$.

KINEROS2 nadalje prikazuje i Manning-ov i Chezy-jev izraz preko opšteg oblika:

$$
q=\alpha h^{m}
$$

Ako se krene od Manning-ove formule:

$$
u=\frac{1}{n} R^{\frac{2}{3}} \sqrt{S_{0}}=\frac{1}{n} h^{\frac{2}{3}} \sqrt{S_{0}} \rightarrow q=\frac{\sqrt{S_{0}}}{n} h^{\frac{5}{3}}
$$

odnosno ako se krene od Chezy-jeve formule:

$$
u=C \sqrt{S_{0}} h^{\frac{1}{2}} \rightarrow q=C \sqrt{S_{0}} h^{\frac{3}{2}}
$$

$$
\begin{aligned}
& \alpha=\frac{\sqrt{S_{0}}}{n}, \mathrm{~m}=5 / 3-\text { za otpore trenja računate po Manning-ovoj formuli, } \\
& \alpha=C \sqrt{S_{0}}, \mathrm{~m}=3 / 2-\text { za otpore trenja računate po Chezy-jevoj formuli, }
\end{aligned}
$$

gde je $n$ Manning-ov koeficijent hrapavosti $\left(\mathrm{m}^{-1 / 3} \mathrm{~s}\right), R$ hidraulički radijus $(\mathrm{m}), C$ Chezyjev koeficijent $\left(\mathrm{m}^{-1 / 2} / \mathrm{s}\right)$. 


\subsection{Model erozije}

Većina modela navedena u literaturi [2], za model erozije, koristi jednačinu održanja mase nanosa u kojoj je difuzioni član zanemaren. Jednačina održanja mase nanosa je data sledećim izrazom:

$$
\frac{\partial(A C)}{\partial t}+\frac{\partial(Q C)}{\partial x}=S_{r}+S_{e}-S_{d}
$$

gde je $C$ koncentracija sedimenata (-), $Q$ protok $\left(\mathrm{m}^{3} / \mathrm{s}\right), A$ površina poprečnog preseka $\left(\mathrm{m}^{2}\right), t$ vreme (s), $x$ dužina $(\mathrm{m}), S_{r}$ erozija kišom $\left(\mathrm{m}^{2} / \mathrm{s}\right) S_{e}$ erozija od suspenzije sa dna $\left(\mathrm{m}^{2} / \mathrm{s}\right), S_{d}$ deponovanje iz suspenzije na dno $\left(\mathrm{m}^{2} / \mathrm{s}\right)$.

\section{- $\quad$ erozija od udara kišne kapi, Sr}

Erozija kišom računa se preko izraza:

$$
S_{r}=C_{f} K(h) i^{2} \quad q>0
$$

gde je $C_{f}$ faktor zavistan od stanja i tipa podloge - parametar kalibracije (1/s) $i$ intenzitet bruto kiše $(\mathrm{m} / \mathrm{s}), K(h)=e^{(-\mathrm{c} h h)}$ redukcioni faktor erozije kišom usled povećavanja dubine $h(-), c_{h}$ parametar kalibracije (-).

\section{- članovi izvora i ponora, $S_{e}$ i $S_{d}$}

U modelu KINEROS2, članovi $S_{e}$ i $S_{d}$ se obračunavaju kao hidraulička erozija $\left(e_{h}\right)$ koja iznosi:

$$
\begin{gathered}
e_{h}=\left(S_{e}-S_{d}\right)=C_{g}\left(C_{m}-C\right) B h \\
C_{g}=\frac{W_{f}}{h}
\end{gathered}
$$

gde je $w_{f}$ brzina tonjenja čestice $(\mathrm{m} / \mathrm{s}), h$ dubina $(\mathrm{m})$.

U modelu KINEROS2 brzina tonjenja je računata preko sledećih izraza:

$$
\begin{aligned}
& w_{f}^{2}=\frac{4 g\left(\rho_{s}-1\right)}{3 C_{D}} d \\
& C_{D}=\frac{24}{R_{n}}+\frac{3}{\sqrt{R_{n}}}+0.34
\end{aligned}
$$




$$
R_{n}=\frac{w_{f} d}{v}
$$

gde je $\rho_{s}$ bezdimenzionalna gustina zrna (-), $C_{D}$ koeficijent sile otpora (-), $R_{n}$ Reynolds-ov broj čestice (-), $v$ kinematski koeficijent vode $\left(\mathrm{m}^{2} / \mathrm{s}\right)$.

Ravnotežna koncentracija nanosa se računa po empirijskim obrascima i generalno je u funkciji brzine i dubine toka. Model KINEROS2 koristi obrazac [7]:

$$
C_{m}=\frac{0.5}{g\left(\gamma_{s}-1\right)^{2}} \sqrt{\frac{S h}{g}}\left(u S_{o}-0.004\right)
$$

Dakle, ukoliko je $u S_{0}<0.004$, transportni kapacitet je jednak nuli.

\section{OPIS INSTALACIJE I METODE}

Za određivanje vremena podizanja hidrograma, trajanja stacionarnog stanja i recesione grane hidrograma izvršena su merenja u trajanju kiše od tri minuta sa uzorkovanjem suspenzije na svakih 10 sekundi u toku prvog minuta i nakon prestanka kiše, odnosno na svakih $20 \mathrm{~s}$ za vreme stacionarnog stanja. Merenja su vršena na laboratorijskoj instalaciji [3], na tabli dužine 4.5 metara (kalibracioni set) i 2.5 metra (verifikacioni set), pod nagibom od $10 \%$ i pri kiši intenziteta $3.1 \mathrm{~mm} / \mathrm{min}$. Izvršeno je po 5 merenja za kalibracioni odnosno verifikacioni set.

U modelu oticaja, u odnosu na model KINEROS2, izvršena je promena načina obračuna trenja. U originalnom modelu KINEROS2, obe formule za obračun trenja su zapravo dobijene za turbulentni režim tečenja, tako da koeficijenti trenja iz ovih formula, ako se određuju prema preporukama iz literature, mogu dati nerealne vrednosti. Zbog toga su razmatrane i druge mogućnosti, odnosno definisanje otpora trenja na osnovu analitičkih rešenja za laminarno tečenje, odnosno teorijskih logaritamskih rasporeda brzina za turbulentno tečenje.

U modelu erozije, izvršena je promena načina obračuna članova izvora i ponora kao i transportne jednačine.

\section{- $\quad$ model oticaja}

Za laminarno tečenje između dve paralelne ploče koeficijent trenja se dobija na osnovu analitičkih rešenja:

$$
\lambda=\frac{24}{\operatorname{Re}}
$$

gde je Re Reynolds-ov broj (-).

84 | JOURNAL OF FACULTY OF CIVIL ENGINEERING 28 (2015) | 
Za turbulentno tečenje između dve paralelne ploče, koeficijent trenja se dobija na osnovu teorijsko-eksperimentalnih zakonitosti za logaritamski raspored brzina, i to za tzv. gladak zid u obliku:

$$
\sqrt{\frac{8}{\lambda}}=2.5 \ln \left(\operatorname{Re} \sqrt{\frac{\lambda}{8}}\right)+3
$$

a za hrapav zid u obliku:

$$
\frac{8}{\sqrt{\lambda}}=2.5 \ln \left(\frac{h}{k}\right)+6
$$

gde je $h$ dubina (m), $k$ apsolutna hrapavost (m).

Izraz ( 26 ) se može preraditi u:

$$
\frac{1}{\sqrt{\lambda}}=2.03 \log (1.17 \operatorname{Re} \sqrt{\lambda})
$$

a izraz ( 27 ) kao:

$$
\frac{1}{\sqrt{\lambda}}=2.03 \log \left(\frac{11.07 \mathrm{~h}}{k}\right)
$$

Kombinacijom izraza ( 28 ) i ( 29 ) može se dobiti objedinjena zavisnost za turbulentno tečenje (i gladak i hrapav zid):

$$
\frac{1}{\sqrt{\lambda}}=-2.03 \log \left(\frac{0.85}{\operatorname{Re} \sqrt{\lambda}}+\frac{k}{11.07 h}\right)
$$

Ovako dobijeni izrazi za koeficijent trenja, u zavisnosti od režima tečenja, mogu se uvrstiti u jednačinu ( 9 ).

Za slučaj turbulentnog tečenja:

$$
u=\sqrt{\frac{8 g}{\lambda}} \sqrt{S_{0} R}=\sqrt{\frac{8 g S_{0}}{\lambda}} h^{\frac{1}{2}}
$$

i za laminarno tečenje: 


$$
\lambda=\frac{24}{\operatorname{Re}}=\frac{24 v}{u h}
$$

sledi:

$$
u=\sqrt{\frac{8 g S_{0} u h}{24 v}} h^{\frac{1}{2}} \Rightarrow q=\frac{8 g S_{o}}{24 v} h^{3}
$$

\section{- model erozije}

U odnosu na model KINEROS2, u modelu erozije, članovi izvora i ponora će se obračunati na sledeći način:

$$
D=w_{f} C
$$

odnosno:

$$
E=w_{f} C_{m}
$$

gde je $D$ tonjenje suspendovanih čestica brzinom wf na dno $(\mathrm{m} / \mathrm{s}), E$ podizanje čestica sa dna $(\mathrm{m} / \mathrm{s}), C_{m}$ ravnotežna koncentracija po kojoj je $E=D$.

Brzina tonjenja će se sračunati preko empirijskih izraza [4]:

$$
\begin{aligned}
& W_{f}=\frac{g \cdot \Delta \cdot \mathrm{d}_{s r}^{2}}{18 \cdot v} \quad \mathrm{~d}_{s r}<0.0001 \mathrm{~mm} \\
& W_{f}=\frac{10 v}{d_{s r}}\left[\left(\frac{1+\left(0.01 \cdot g \cdot \Delta \cdot d_{s r}^{3}\right)}{v^{2}}\right)^{0.5}-1\right] \quad 0.0001<d_{s r}<0.001 \\
& W_{f}=\sqrt{1.1 \cdot g \cdot \Delta \cdot d_{s r}} \quad d_{s r}>0.001
\end{aligned}
$$

gde je $\Delta$ relativna gustina nanosa $(-), d_{s r}$ prosečan prečnik zrna (m).

Umesto izraza ( 24 ) transportni kapacitet će se obračunati i preko obrazca EngelundHansen-a [1]: 


$$
C_{m}=\frac{0.5 u u_{*}^{3}}{g^{2} d h\left(\gamma_{s}-1\right)^{2}}
$$

gde je $u *$ brzina trenja $(-), g$ gravitaciono ubrzanje $(\mathrm{m} / \mathrm{s}), d$ prečnik zrna sedimenta $(\mathrm{m}), \gamma$ specifična težina zrna sedimenta (-).

$$
u_{*}=\sqrt{\frac{\tau}{\rho}}=\sqrt{\frac{\rho g h S_{o}}{\rho}}=\sqrt{g h S_{0}}
$$

Kada se obrazac ( 38 ) uvrsti u ( 37 ) dobija se:

$$
C_{m} \frac{0.5 u\left(g h S_{0}\right)^{\frac{3}{2}}}{g^{2} d h\left(\gamma_{s}-1\right)^{2}}=\frac{0.5}{g\left(\gamma_{s}-1\right)} \sqrt{\frac{h S_{0}}{g}} u S_{o}
$$

\section{REZULTATI}

Za simulaciju procesa oticaja i erozije sa laboratorijske instalacije napisan je model koji sadrži samo elemente koji se izučavaju (intenzitet kiše, nagib i dužina sliva). U prvom koraku, model je napravljen po direktnom ugledu na KINEROS2 a zatim su uvedene modifikacije u načinu proračuna otpora trenja. Rezultati kalibrisanog modela koristi Manning-ov izraz za proračun trenja i modela koji koristi analitički izraz za proračun otpora trenja su upoređeni a rezultati su prikazani na slici 1.
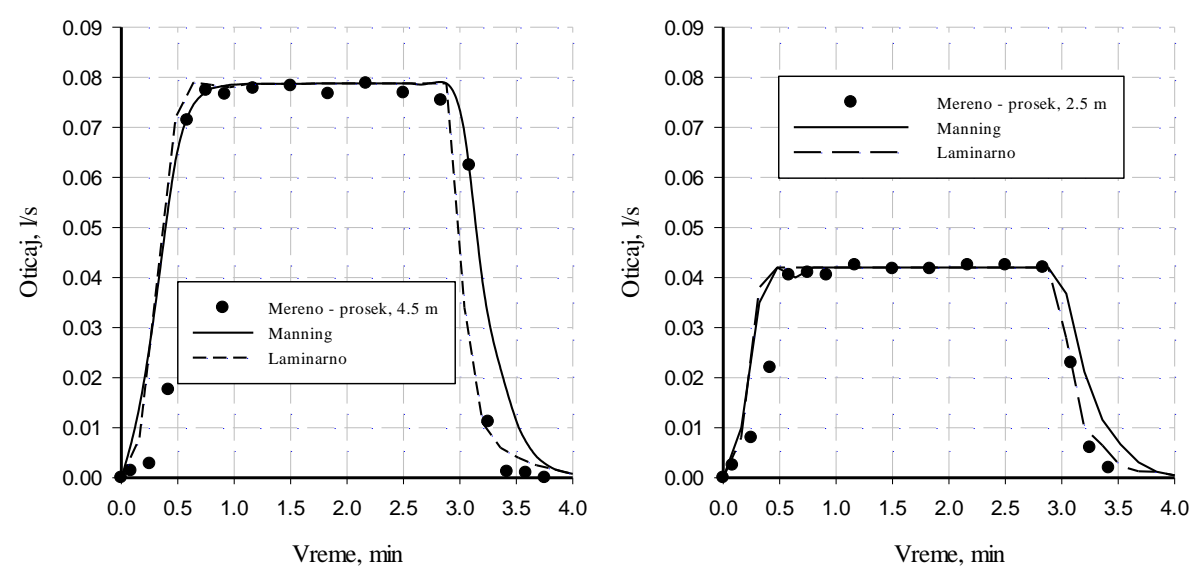

Slika 1. Uporedni prikaz merenih i protoka dobijenih modelom: kalibracioni set (levo) $i$ verifikacioni set (desno) 
Model KINEROS2 je kalibrisan na osnovu Manning-ovog koeficijenta hrapavosti i koeficijenta filtracije. Zadržana je originalna vrednost parametra $\mathrm{m}$ po Manning-ovoj jednačini od $m=5 / 3$, infiltracija obračunata preko koeficijenta oticaja a Manningov koeficijent iznosin $=0.015 \mathrm{~m}^{-1 / 3} \mathrm{~s}$.

U modelu koji trenje obračunava preko analitičkog izraza za laminarno tečenje zadržana je originalna vrednost parametra $m=3$ a infiltracija je obračunata preko koeficijenta oticaja.

Kako model koji trenje obračunava analitičkim izrazom za laminarno tečenje bolje prati merene vrednosti oticaja, naročito na recesionoj grani hidrograma, dalje analize su rađene korišćenjem ovog modela proračuna otpora trenja.

Kako bi se utvrdio uticaj metode za proračun transportnog kapaciteta, modelisani su erozija i transport nanosa na osnovu izraza ( 24 ) i na osnovu izraza ( 39 ) a rezultati su prikazani na slici 2. Kao faktor kalibracije modela erozije poslužio je faktor erodibilnosti zemljišta, $C_{f}$., sa vrednošću od 70000 .
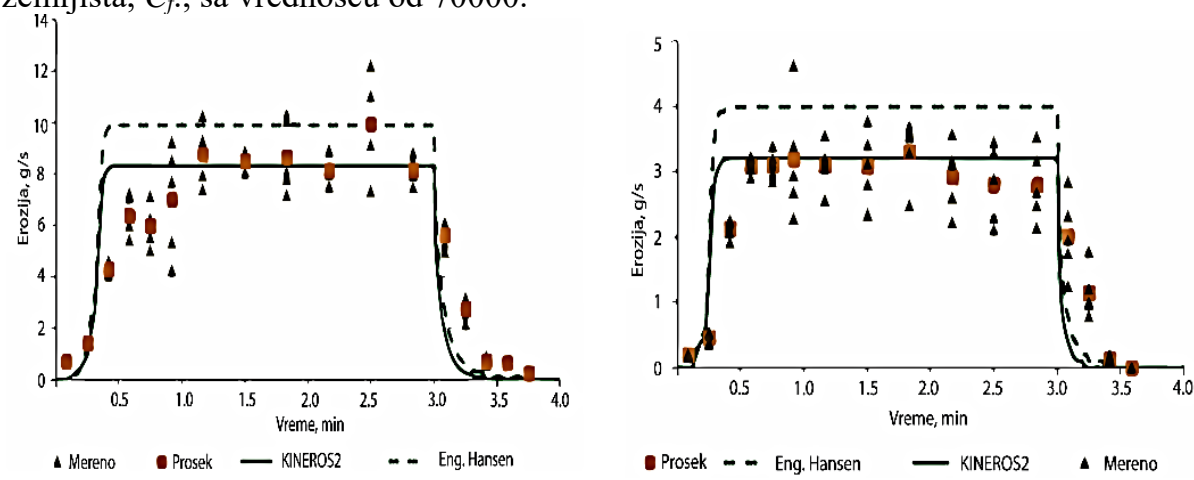

Slika 2. Proračun erozije na osnovu jednačina ( 24 ) i (39) za laminarno tečenjekalibracioni set (levo) $i$ verifikacioni set (desno)

\section{DISKUSIJA I ZAKLJUČCI}

$\mathrm{Na}$ osnovu rezultata dobijenih modelom za kalibracioni i verifikacioni set merenja uočljivo je da oba modela daju iste vrednosti maksimalnog protoka. Posmatrajući grane podizanja i opadanja hidrograma uočljivo je da model sa analitičkim izrazom za proračun otpora trenja u laminarnoj zoni nešto bolje prati merene rezultate od modela zasnovanog na Manning-ovom izrazu.

Razlike u modelima su uočljivije ukoliko se uporede brzine tečenja. Modelom sa analitičkim izrazom za otpore trenja za laminarno tečenje dobijaju se veće brzine tečenja vode u odnosu na model sa Manning-ovim izrazom. Navedene razlike u brzinama vode direktno utiču i na pronos nanosa pa je zaključak da je, u konkretnom slučaju, za model oticaja bolje koristiti model laminarnog tečenja jer će, bez obzira na iste vrednosti protoka, dati dubinu i brzinu vode na osnovu originalnih, nekalibrisanih, jednačina.

Model sa laminarnom pretpostavkom daje najveće vrednosti erozije za oba seta merenja. Ovo je, s obzirom na činjenicu da taj model daje najveće brzine, bilo očekivano. Model 
zasnovan na Manning-ovoj jednačini proračuna otpora zahteva dodatnu kalibraciju kako bi se dobila ista količina erozije kao kod navedenog modela.

Na osnovu slike 2 se zaključuje da se, s obzirom na „šaranje“ rezultata, oba izraza za transportni kapacitet mogu uspešno koristiti.

\section{ZAHVALNOST}

Rezultati istraživanja prezentovani u ovom radu su dobijeni u okviru naučnog projekta broj TR 37010 "Sistemi za odvođenje kišnih voda kao deo urbane i saobraćajne infrastrukture" koji finansira Ministarstvo prosvete i nauke Republike Srbije.

\section{LITERATURA}

[1] Engelund FA, Hansen E. Monograph on sediment transport in alluvial streams. Teknisk forlag; 1967.

[2] Gabrić O, Horvat M, Horvat Z. Kratak pregled modela oticaja i erozije zasnovanih na fizičkim procesima. Zbornik radova Građevinskog fakulteta, Subotica. 2015;27:171-182.

[3] Gabrić O, Plavšić J. Prikaz i analiza rezultata merenja erozije u laboratorijskim uslovima. U: Zbornik radova 17. naučnog savetovanja Srpskog društva za hidraulička istraživanja (SDHI) i Srpskog društva za hidrologiju (SDH). Beograd: Građevinski fakultet Univerziteta u Beogradu; 2015.

[4] Jovanović MB. Regulacija reka: rečna hidraulika i morfologija. Građevinski fakultet; 2002.

[5] Jovanović S. Hidrologija. Beograd: Naučna knjiga; 1990.

[6] Kalin L, Hantush MM. Assessment of two physically-based watershed models based on their performances of simulating water and sediment movement" [Internet]. U: Conference Proceedings, 1st Interagency Conference on Research in the Watersheds (ICRW), Benson, AZ. 2003 p. 27-30.

[7] Semmens DJ, Goodrich DC, Unkrich CL, Smith RE, Woolhiser DA, Miller SN. KINEROS2 and the AGWA modelling Framework [Internet]. U: Hydrological Modelling in Arid and Semi-Arid Areas. Cambridge University Press; 2007.

[8] Smith RE, Goodrich DC, Unkrich CL. Simulation of selected events on the Catsop catchment by KINEROS2: a report for the GCTE conference on catchment scale erosion models. Catena. 1999;37(3):457-475.

\section{CALIBRATION AND VERIFICATION OF NUMERICAL RUNOFF AND EROSION MODEL}

Summary: Based on the field and laboratory measurements, and analogous with development of computational techniques, runoff and erosion models based on equations which describe the physics of the process are also developed. Based on the KINEROS2 
model, this paper presents basic modelling principles of runoff and erosion processes based on the St. Venant's equations. Alternative equations for friction calculation, calculation of source and deposition elements and transport capacity are also shown. Numerical models based on original and alternative equations are calibrated and verified on laboratory scale model. According to the results, friction calculation based on the analitic solution of laminar flow must be included in all runoff and erosion models.

Keywords: erosion, model, runoff 